\title{
Editorial
}

\section{2: a successful year for Nutrafoods}

\author{
Andrea Poli, Franca Marangoni
}

Correspondence to: Andrea Poli

poli@nutrition-foundation.it

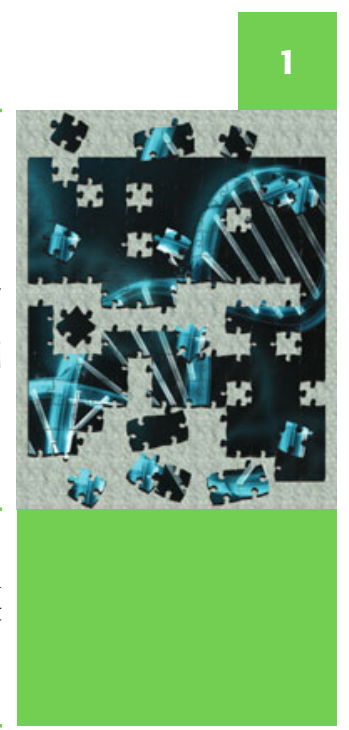

(C) Springer Healthcare - CEC Editore 2013

It has been one year since we accepted Springer and CEC's invitation to serve as editors of this journal. Time flies and we can now state that 2012 was a successful year for Nutrafoods. Our journal has already achieved the goal of being perceived, in the wide market of scientific publishing, as an authoritative international, peer-reviewed journal focusing on nutraceuticals and dietary food supplements, herbals, functional foods and beverages. We have thus far published four issues, with 16 papers selected from many more submitted articles; well known authors contributed to each issue with papers and invited commentaries.

About 4500 full text articles were downloaded in 2012, mainly in Asia-Pacific (37\%), Europe (29\%) and North America (20\%). This confirms the international nature of Nutrafoods and its ability to reach out to a large and diversified readership.

Notably, starting from January 2013, the "OnLineFirst" service has been implemented: articles accepted for publication will be published online before being included in the regular printed issue. Online publications are fully citable by using DOI numbers and, therefore, increase the speed of dissemination. In 2013, we will continue improving the scientific standard of Nutrafoods, while paying attention to its worldwide readership. In particular, our editorial goal is to widen the journal's focus to include specific health aspects related to food intake.

At this time, we would like to thank our publisher Springer and CEC Editore for supporting us during this difficult and challenging year. Also, our gratitude goes to the whole editorial board, to our reviewers and to the editor of the Scientific and News Updates sections: they play a crucial role in helping us improving the scientific standard and diffusion of the journal.

To further build a successful journal, we would like to invite all of our readers to submit reviews and research articles to Nutrafoods. We will be pleased to consider such papers for publication and we will strive to further optimise our already rapid turnaround time.

\section{Franca Marangoni \\ Andrea Poli \\ Co-editor \\ Editor-in-Chief}

\section{Conflict of interest}

Andrea Poli and Franca Marangoni declare that they have no conflict of interest. 